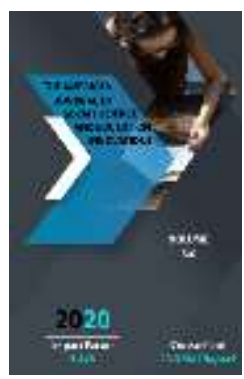

\title{
Develop The Pronunciation And Speech Of Small-Age Students On The Basis Of A Creative Approach
}

\author{
Buvajonova Mohiraxon Usmonali Qizi \\ Teacher Of The Department Of Primary Education Methodology Of Fergana State University, \\ Fergana Region, Uzbekistan
}

\begin{abstract}
Journal Website: http://usajournalshub.c om/index,php/tajssei

Copyright: Original content from this work may be used under the terms of the creative commons attributes 4.0 licence.
\end{abstract}

\section{ABSTRACT}

As a global medium of communication, the importance of English has increased a lot in the present social, political and commercial contexts. With the advancements of Information technology in various spheres of society, English has become the only language for the world citizen. In Uzbekistan, English has long been taught as a core subject from class $1-12$, yet it is very painful to watch that students are still lagging behind to achieve comprehensive productive skills, that is writing and speaking skills. For a long time, communicative method is followed at schools and colleges that aims at developing four skills reading, writing, listening and speaking. Proper planning, implementation and monitoring can make it possible to achieve students' language proficiency in four skills simultaneously. This paper focuses on the challenges and possible solutions on the way of effective application of productive skills.

\section{KEYWORDS}

Speech, Influence, Dynamic processes, establish communication

\section{INTRODUCTION}

The subject of speech psychology is a phrase from which the structure and function of speech pronouns, establish communication with other people, express their feelings with the help of Speech, Influence on others.

At the beginning of the XIX century, speech began to be studied in linguistics, which reached the level of independent science. One of the authors who studied the psychological nature of the language, evaluating it as a manifestation of the human psyche, V.Gumbol'dt was. He looks at it as a result of constant birth, not a dead product. Gumbol'tt research provides an opportunity to study the 
problems of language-speech thinking understanding, the formation of logical and linguistic categories, the relationship of the thinking process with the material (Sound) substrate. V.Gumboldt's psychological research in his confused linguistics co-founder of the psychological direction Developed by sternal.

With the formation of psychology as an independent science in the second half of the XIX century, the problem of language and speech also began to be studied in psychological research.

V. Wundt paid special attention to the psychological, psychophysiological aspects of speech in the psychology of his Peoples. Oral speech is put in a row by actions that express the feelings of a person.

V. Wundt's book, published in 1900-year, speech was viewed as a means of communication - communication, giving an understanding of its psychological, psychophysiological linkage, and therefore, for the time being, grief has maintained its scientific significance.

\section{MATERIALS AND METHODS}

Later, language and speech began to be studied theoretically-practically. One of the most important works in this area is L.S.Vigotsky's book" thought and speech " (1934). The central idea of this book is the confirmation of the social nature of speech, its capabilities as a means of treatment. L.S.Vigotsky views thought and speech as a holistic dialectical Union. The idea is not only expressed in words, but also achieves perfection. The transition from thought to speech is the division of thought into parts and expression in a word.
P.P.While Blonsky emphasizes the indestructible connection of thought and speech, it is also true that they are not exactly the same thing. He I.P.Based on Pavlov's teaching about conditional reflexes, he pays special attention to the signaling nature of the word.

S.L.Rubinshteyn this unity, showing the connection of speech with consciousness, reflects the social nature of human consciousness. Speech is a form of the existence of thoughts, feelings of a person who speaks for another person. The word is born in communication and puts forward the idea that it serves for communication.

V.M. In the Bakhtaran laboratory, speech, based on theoretical teachings, was studied experimentally. Through the study of groups of children 4-15 years of age, developed a methodology for the analysis of monocot and speech products. Individual characteristics of children's speech were studied. One of the most important areas of speech psychology is the study of the acoustic side of speech. Speech Acoustics are also studied by physical acoustics, linguistic phonetics, cybernetics, and other sciences. Speech to a psychologist a peacock is the result of the activity of the articular apparatus of a person speaking. This activity is constantly under the control of the hearing analyzer and is controlled by special departments of the human brain, motor commands.

In the laboratory under the leadership of Artoo, methods and apparatus for studying speech acoustics were developed. An electrodynamic recorder for learning how to pronounce a tone and sentence, an automatic analyzer of speech sounds - a spectrograph, sentence for recording articulation. for 
experimental research, acoustic phenomena tone, sound, phoneme and joints were also covered. These phenomena are psychologically studied from the side of speech perception, acquaintance and understanding.

\section{DISCUSSIONS AND RESULTS}

The study of the acoustics of speech is also associated with its external expression of the greater part. But the researchers are also interested in its internal aspect. Therefore, many laboratory methods have been developed, aimed at studying the dynamics of internal speech. One of such methods, aimed at studying the activity of internal speech, is the use of the method of electromyography in the registration (recording) of hidden movements of the articulation organs (language, lab). A.M. Built by Sokolov through the interaction of internal speech and language, recording my gram of the muscles of the tongue and the lower lip in the process of solving various mental tasks. As it turned out in the experiment, the activity of articulation also increases as the mental activity becomes more complicated. To study the dynamics of the internal speech process, a method of Central and peripheral effects is developed. N.Y.I. The method of Central speech influences was imitated by Jenkin. In the process of experimentation, the examiners-making sentences, counting geometrical forms, at the same time multiplying the numbers, knocked on the given rhythm with their empty hands. The introduction of another rhythm, which is not associated with internal speech, has a braking effect. As a key indicator, the time spent on solving the main task, the correctness of the solution, the rhythm and the speed of knocking are taken as a basis. The results obtained allowed to distinguish static and dynamic parts in the structure of the speech mechanism. The composition of each speech is a continuous and modeled character embodiment in the sound, word, sentence. Dynamic processes play an important role in making sentences from words.

The psychophysiological approach to the study of speech is determined depending on the direction of the components of the speech process. N.B.A. order for Jenkin to learn how to pronounce using the method of dynamic radiography-electrocardiogram, my gram, skingalvanic reaction, in the use of techniques for studying the frequency of heart contractions. Such methods are used for the purpose of studying the features of articulation during logo neurosis and retention (stammer).

The formation of attitude motivation to educational activities in junior school age students is directly related to a large number of socio - psychological factors, including the general orientation of the individual. Because, the analysis of scientific literature has shown that the attitude to educational activity begins and develops primarily from the attitude to oneself, to others and to the results of activities. Of course, it is also important in this process that the individual is self - sufficient, the educational process, the individual characteristics of the individual, the correct Organization of educational activities on the basis of pedagogical and psychological requirements. In the above chapters, the information about this process and the methods used to research this process is described in detail (chapters one and two). In this paragraph, we have focused more on the analysis of empirical data obtained through appropriate methodological approaches and methods and on the issue of maintaining a certain level of socio - psychological feedback on this basis. Of course, the formation of 
attitude motivation, based on the general orientation of the individual, is a wide-ranging process. This process cannot be fully resolved through a detailed and comprehensive review only the results of one study. In this regard, in this study, we have drawn serious attention to one aspect of the issue, that is, only the general orientation and values of the individual lying at the time of the formation of attitude motivation. In the course of the study, we took advantage of the role of specific questionnaire questions, tests, individual and group interviews, short - and long-term observations, practical and methodical work of well-known psychologists known in the scientific press, which determine each criterion. Each obtained primary and secondary result was conditionally analyzed through a system of points received in a special order. And the analysis of this order allowed to have the following data:

- To interpret the process of attitude as an object of general orientation of the individual and the corresponding values.

- Empirical assessment of the proportion between attitude motivation and reader personality activity.

- To determine the indicators of attitude motivation formed on the basis of the general orientation of the individual (self, People, activity).

- To describe the relevant sociopsychological conclusions based on the analysis of the obtained empirical materials.

We think that all of the above tasks will allow us to draw appropriate scientific conclusions about the indicators of attitude motivation, which will represent the overall interpretation of the study.

\section{REFERENCES}

1. Brown, H.D. (1994) Teaching by principles: An interactive approach to language.

2. Brown, H. D. (2000). Principles of language learning and teaching (4th ed.). New York: Longman. Brown, Nation.

3. "Teaching Speaking: Suggestion for the Classroom." 4 January 2008 http://jaltpublications.org/tlt/files/97/jan/sp eaking.html> Chastain, K. (1998).

4. Developing second language skills (2nd Ed.). Chicago: Harcourt Brace Publishers. Cohen \&Manion. (1994). Research methods in education fourth edition. United States and Canada, Reprinted. Creswell, J. W. (2002). 